Check for updates

Cite this: RSC Adv., 2018, 8, 27754

Received 28th May 2018

Accepted 28th July 2018

DOI: $10.1039 / \mathrm{c} 8 \mathrm{ra04547j}$

rsc.li/rsc-advances

\section{A study on fabrication of PVDF-HFP/PTFE blend membranes with controllable and bicontinuous structure for highly effective water-in-oil emulsion separation $\dagger$}

\begin{abstract}
Xinya Wang, ${ }^{\text {ab }}$ Changfa Xiao, (D) *ab Hailiang Liu, ${ }^{\text {ab }}$ Mingxing Chen, ${ }^{\text {ab }}$ Junqiang Hao ${ }^{\text {ac }}$ and Yanjie $\mathrm{Wu}^{\mathrm{ac}}$

In this study, poly(vinylidene fluoride-co-hexafluropropylene) (PVDF-HFP)/polytetrafluoroethylene (PTFE) blend membranes for water-in-oil emulsion separation were prepared via a thermally induced phase separation (TIPS) method using dibutyl phthalate (DBP) and dioctyl phthalate (DOP) as a mixed diluent. The effects of PTFE content on the obtained membranes' structure and properties were studied. The results showed that the surface structure of the obtained membranes without addition of PTFE particles was denser and the surface pores got smaller. The porosity, pore size and hydrophobicity obviously increased with the increase in PTFE content. However, the breaking elongation and breaking strength decreased with the increase of PTFE content. When the PTFE content was $10 \mathrm{wt} \%$, the obtained membrane showed the highest separation efficiency for different kinds of water-in-oil emulsions. In addition, the antifouling performance of the obtained membranes was also studied for many times of reuse. This paper introduces an effective and facile method to prepare hydrophobic-oleophilic membranes for water-in-oil emulsion separation.
\end{abstract}

\section{Introduction}

Oily wastewater is produced by many industrial processes, such as those of the steel industry, machining and food industry, and by oil leaks, etc. ${ }^{1-3}$ It brings various environmental problems and damages human health. ${ }^{4}$ Thus, research about oil-water separation is becoming more and more significant. To date, membranes have been applied for treatment of oily wastewater owing to their many advantages, ${ }^{5}$ such as high efficiency, simple process, low cost, environmental protection, etc. For oil/water separation, the membrane materials need to possess selective wettability (hydrophilic-oleophobic or hydrophobic-oleophilic). ${ }^{6,7}$ For water-in-oil emulsion separation, membranes are fabricated by using hydrophobic-oleophilic materials, such as poly(tetrafluoroethylene) (PTFE) ${ }^{8}$ poly(vinylidene fluoride) (PVDF), ${ }^{\mathbf{9}, 10}$ poly(ethylene chlorotrifluoroethylene) (ECTFE), ${ }^{\mathbf{1 1}}$ polypropylene (PP), ${ }^{12}$ etc. Recently, an emerging fluoro-

${ }^{a}$ State Key Laboratory of Separation Membranes and Membrane Processes, Tianjin Polytechnic University, No. 399, Binshui Road, Xiqing District, Tianjin, 300387, P. R. China. E-mail: xiaochangfa@163.com; Tel: +08602283955299

${ }^{b}$ School of Material Science and Engineering, Tianjin Polytechnic University, No. 399, Binshui Road, Xiqing District, Tianjin 300387, P. R. China

${ }^{c}$ School of Textiles, Tianjin Polytechnic University, No. 399, Binshui Road, Xiqing District, Tianjin 300387, P. R. China

$\dagger$ Electronic supplementary information (ESI) available. See DOI: 10.1039/c8ra04547j copolymer, PVDF-HFP has been attracting more and more attention. Compared with PVDF, PVDF-HFP has better properties, such as higher solubility, higher hydrophobicity and better mechanical strength, owing to the combination with hexafluropropylene (HFP). ${ }^{13-15}$

PVDF-HFP membranes prepared via non-solvent induced phase inversion separation (NIPS) method have dense surface and are applied in many processes, such as membrane distillation, ${ }^{16}$ gas absorption, ${ }^{17}$ batteries, ${ }^{18}$ etc. To date, few literatures report PVDF-HFP membranes fabricated via thermally induced phase separation (TIPS) method. Ji et al. ${ }^{19}$ and Cui et al. ${ }^{\mathbf{2 0 , 2 1}}$ prepared PVDF-HFP membranes for lithium ion battery via TIPS method. Cao et $a .^{22}$ fabricated the PVDF-HFP porous membrane by supercritical $\mathrm{CO}_{2}$ extraction of DBP template from PVDF-HFP/DBP film. However, but none of them made mention of their hydrophobic-oleophilic properties. As we all know, the structure and hydrophobicity of membrane play an important role during water-in-oil emulsions separation process. ${ }^{23}$ In our previous study, ${ }^{24}$ we know that the pure PVDFHFP membranes prepare via TIPS method have dense structure and deficient hydrophobicity with a contact angle of $125 \pm$ $2.38^{\circ}$. Therefore, many researchers focus on modification method of PVDF-HFP membranes. Blending method with filmforming polymer is a facile and efficient method to fabricate novel membranes with desirable structure and selective wettability. ${ }^{25-27}$ In order to get PVDF-HFP membrane with sufficient 
hydrophobicity, we select PTFE as the blending polymer owing to its outstanding hydrophobicity. ${ }^{28}$ Additionally, PTFE possesses excellent stability and can disperse in many organic and inorganic solvents without degradation. ${ }^{29}$ To the best of our knowledge, the preparation of PVDF-HFP/PTFE blend membranes via TIPS method has not been reported previously.

In this study, PVDF-HFP/PTFE blend membranes were prepared for the first time via TIPS method. The introduction of PTFE particles had a significant improvement on structure and performance of obtained membrane. The effects of PTFE content on the rheological properties of casting solution was discussed. In addition, the morphologies, surface properties, selective wettability, mechanical properties and permeability of PVDF-HFP/PTFE blend membranes were investigated.

\section{Experimental}

\subsection{Materials}

PVDF-HFP (Kynar2500, $\approx 18$ mol\% HFP), semi-crystalline copolymer, was purchased from Arkema (Singapore) and PTFE particles (MP1300, particle size $=40 \mathrm{~nm}$ ) was purchased from DuPont (America). Dibutyl phthalate (DBP, b.p. $340{ }^{\circ} \mathrm{C}$ ), dioctyl phthalate (DOP, b.p. $386^{\circ} \mathrm{C}$ ) and alcohol were purchased from Tianjin Kermel Chemical Reagent Co. Ltd.

\subsection{Preparation of PVDF-HFP/PTFE blend membranes}

Measured amounts of PVDF-HFP, PTFE and mixed diluent (DBP and DOP) were fed to the vessel and stirred at $150{ }^{\circ} \mathrm{C}$ for approximately $4 \mathrm{~h}$ to obtain casting solution. After standing for almost $3 \mathrm{~h}$ with atmospheric pressure, the bubble in the solution can be removed. The casting solution was casted onto the pre-clean glass substrate with a thickness of $200 \mu \mathrm{m}$ at $170{ }^{\circ} \mathrm{C}$ and then the glass substrate was directly quenched in cool water bath $\left(5{ }^{\circ} \mathrm{C}\right)$. Afterwards, the remaining diluent in films was extracted by absolute ethanol which was then removed by immersing in distilled water. Finally, the membranes were dried at $-50{ }^{\circ} \mathrm{C}$ using a drier (FD-1A-50, Shanghai, China). In this work, the obtained membranes were named M-E0, M-E1, M-E2, M-E3, M-E4 and M-E5 and the compositions were exhibited in Table 1.

\subsection{Preparation of water-in-oil emulsions}

In order to obtain surfactant-free emulsions, $1 \mathrm{~mL}$ pure water was added dropwise into $100 \mathrm{~mL}$ diesel or kerosene and vigorously stirred for at least $6 \mathrm{~h}$. After standing for 1 day, the

Table 1 The compositions of PVDF-HFP/PTFE blend membranes

\begin{tabular}{lllll}
\hline Membrane & $\begin{array}{l}\text { PVDF- } \\
\text { HFP (wt\%) }\end{array}$ & $\begin{array}{l}\text { PTFE } \\
(w t \%)\end{array}$ & $\begin{array}{l}\text { DBP } \\
(w t \%)\end{array}$ & $\begin{array}{l}\text { DOP } \\
(w t \%)\end{array}$ \\
\hline M-E0 & 30 & 0 & 49 & 21 \\
M-E1 & 25 & 5 & 49 & 21 \\
M-E2 & 22.5 & 7.5 & 49 & 21 \\
M-E3 & 20 & 10 & 49 & 21 \\
M-E4 & 17.5 & 12.5 & 49 & 21 \\
M-E5 & 15 & 15 & 49 & 21
\end{tabular}

surfactant-free emulsions would not cause agglomerate or precipitate.

For surfactant-stabilized emulsions, $0.2 \mathrm{~g}$ span 80 with a hydrophile-lipophile balance (HLB) value of 4.3 was added into $100 \mathrm{~mL}$ diesel or kerosene and vigorously stirred for $0.5 \mathrm{~h}$. Then, $1 \mathrm{~mL}$ pure water was added dropwise into the mixture and stirred vigorously for $6 \mathrm{~h}$ to obtain surfactant-stabilized emulsion. After standing for more than 7 days, no obvious agglomeration and precipitation was observed.

\subsection{Rheological properties of polymer solution}

The rheological properties of polymer solutions were investigated with a rheometer (Haake Mars, Thermo Fisher Scientific, America).The shear rate $(\gamma)$ varied from 1 to $100 \mathrm{~s}^{-1}$ for each sample and test temperature was $150{ }^{\circ} \mathrm{C}$.

\subsection{Membrane characterization}

The dried membranes were fractured in liquid nitrogen. The morphologies of membrane surface and cross-section were observed with SEM (S4800, Hitachi, Japan) after coated with gold. An atomic force microscope (AFM, Agilent-S5500, USA) was employed to analyze the surface properties. The hydrophobicity and lipophilicity of membranes were measured by contact angle goniometer (DSA-100, Kruss, Germany) at room temperature. To obtain average value, the contact angle was performed five times at different locations. Liquid entrance pressure (LEP) of dry flat membrane was measured using a laboratory device at room temperature. Increased the pressure slowly until the water permeated through the membrane, this pressure was considered as the LEP point. Average of the three tests was the LEP of the membrane. The mechanical strength tests of obtained membranes were performed with an electron instrument (YG061F, Laizhou, China). Each membrane was cut into $5 \mathrm{~mm}$ (width) $\times 30 \mathrm{~mm}$ (length) specimen and the tensile rate was $20 \mathrm{~mm} \mathrm{~min}^{-1}$. Five times were performed for every sample. The pore size of obtained membranes was investigated using automatic mercury porosimeter (AutoPore IV-9500, Tektronix, America) and the porosity of membrane was measured by a gravimetric method and calculated as follows:

$$
\varepsilon(\%)=\frac{\left(W_{1}-W_{2}\right) / \rho_{\mathrm{A}}}{\left(W_{1}-W_{2}\right) / \rho_{\mathrm{A}}+W_{2} / \rho_{\mathrm{B}}}
$$

where $\varepsilon(\%)$ was the porosity of the membrane, $W_{1}$ and $W_{2}$ were wet and dry membrane weights, $\rho_{\mathrm{A}}$ and $\rho_{\mathrm{B}}$ were the density of butanol and polymer.

\subsection{Emulsions separation experiments}

The prepared membrane with $12.56 \mathrm{~cm}^{-2}$ effective area was placed on the porous support between feeding bottle and filter tip and carefully sealed by Teflon tape. $20 \mathrm{~mL}$ freshly prepared water-in-oil emulsion including various surfactant-free emulsions and surfactant-stabilized emulsions was poured into the feed liquid bottle. Then, the filtrate gradually permeated through the membrane into the collection bottle under a negative pressure a negative pressure $(-0.1 \mathrm{MPa})$. The filtration rate 

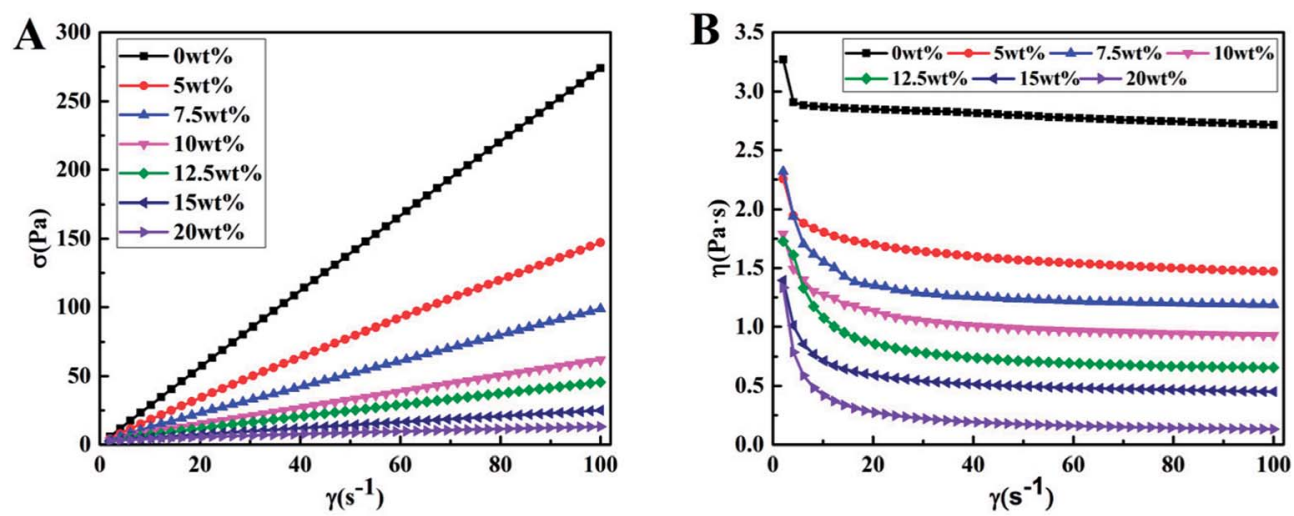

Fig. 1 Effect of PTFE content on $\sigma-\gamma$ curve (A) and $\eta-\gamma$ curve (B).

was measured from the permeated volume of water-in-oil emulsions as a function of time and determined as follows:

$$
J=\frac{V}{S \times t}
$$

where $J$ was filtration rate $\left(\mathrm{L} \mathrm{m}^{-2} \mathrm{~h}^{-1}\right), V$ was permeate volume (L), $S$ was effective area $\left(\mathrm{m}^{2}\right)$ and $t$ was testing time (h).

The separation efficiency of the water-in-oil emulsion was calculated as follows:

$$
R(\%)=\frac{C_{\mathrm{f}}-C_{\mathrm{p}}}{C_{\mathrm{f}}} \times 100 \%
$$

where $C_{\mathrm{f}}$ and $C_{\mathrm{p}}$ were water content of feed and permeate waterin-oil emulsion respectively, $R$ was the separation efficiency. To get the average value, every membrane was tested for at least five times.

The water content in the filtrate was detected by using the Karl Fischer titrator (C20, Mettler Toledo, Switzerland) and then the purity was analyzed to obtain the filter fineness. The photographs of the emulsion and filtrate were obtained by using the Nikon optical microscope (E200, Japan).

\subsection{Antifouling performance}

To evaluate the antifouling performance of the obtained membrane, the filtration rate of the membrane M-E3 for treatment of emulsions separation in 20 cycles was performed. After each cycle, the membrane was carefully taken out and simply washed with ethanol, and then dried in air.

\section{Results and discussion}

\subsection{Rheological properties of dope solution}

As for the blend membranes fabricated via TIPS method, the rheological properties of polymer solutions had an obvious effect on its processibility and had an obvious influence on properties and structure of obtained membrane. ${ }^{30} \mathrm{Fig} .1$ showed the effects of PTFE content on the rheology behavior of polymer solutions. It could be seen that, the shear stress of polymer solution without PTFE particles was much higher than that of the polymer solution with PTFE particles at the same shear rate and the shear stress of polymer solutions decreased continuously with increase of PTFE content. In addition, the viscosity $(\eta)$ of polymer solutions decreased with increase in PTFE content.

In order to further study the effects of PTFE content on the non-Newtonian behavior of casting solution, the nonNewtonian index $(n)$, slope of the curves of logarithm of shear stress versus logarithm of shear rate, was presented in Table 2. According to the value of $n$, the fluid cloud be divided into three classes: dilatant fluids $(n>1)$, Newtonian fluids and pseudo plastic fluids $(n<1)$. When the casting solution without addition of PTFE, the value of $n$ reached 0.987 which showed excellent Newtonian flowing property of the casting solution. As shown in Table 2, the value of $n$ decreased with increase of PTFE content. When PTFE content was $20 \mathrm{wt} \%$, the value of $n$ was 0.448 which indicated that the casting solution has very poor processibility. Taken together, when PTFE content was lower than $15 \mathrm{wt} \%$, the polymer solutions exhibited excellent processibility.

\subsection{Effect of PTFE contents on morphology}

The morphology of obtained membranes prepared with various PTFE contents was shown in Fig. 2. It can be seen clearly that the cross section of obtained membranes presented bicontinuous structure and the structure got looser with increase of PTFE contents. On the other hand, the obtained membrane without blending PTFE particles (M-E0) had relatively dense

Table 2 The non-Newtonian index of different polymer solutions

\begin{tabular}{llllllll}
\hline Temperature $\left({ }^{\circ} \mathrm{C}\right)$ & PTFE content $(\mathrm{wt} \%)$ & 0 & 5 & 7.5 & 10 & 12.5 & 15 \\
\hline 170 & Non-Newtonian index (n) & 0.987 & 0.912 & 0.874 & 0.814 & 0.760 & 0.656 \\
\hline
\end{tabular}



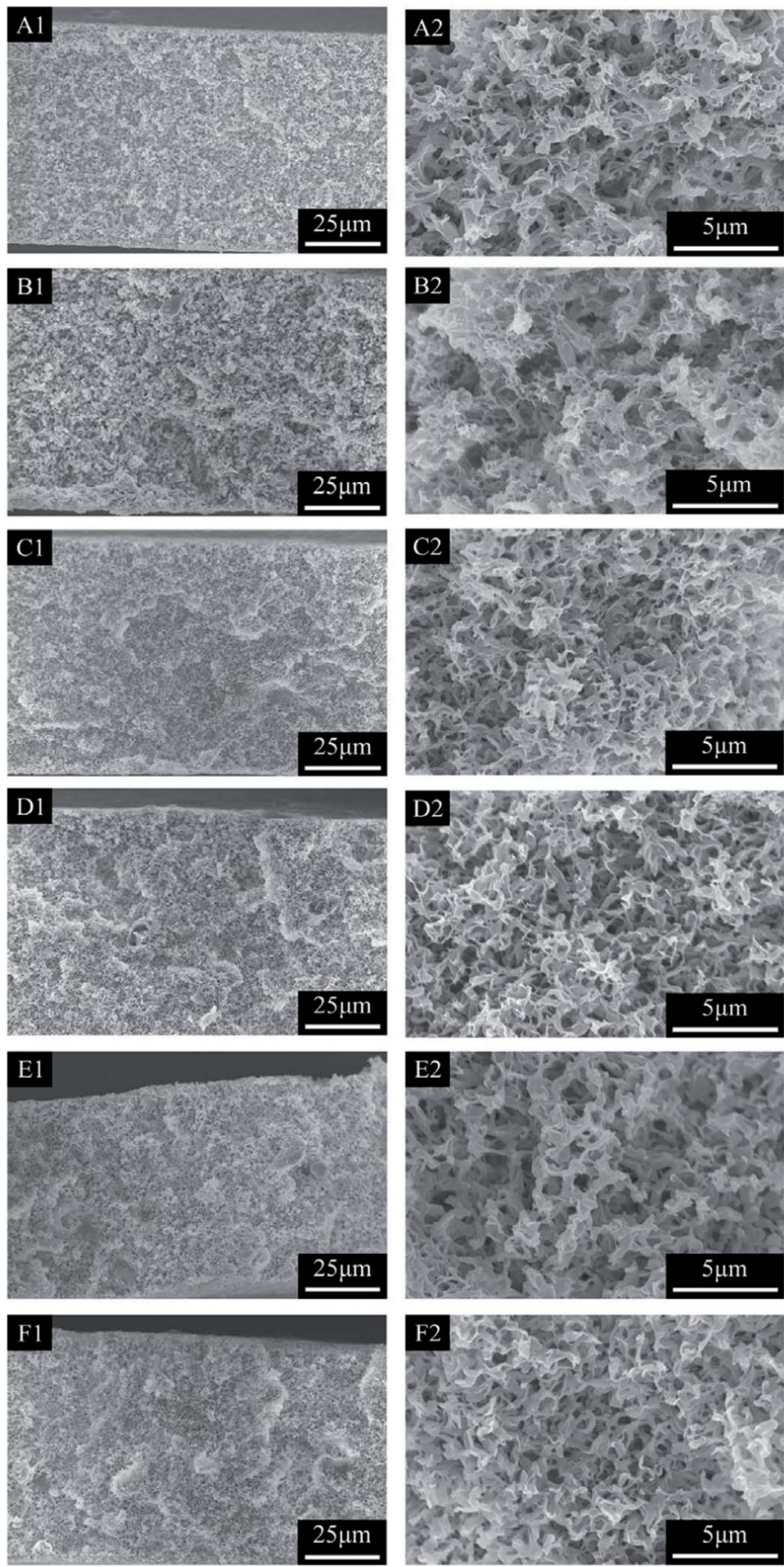
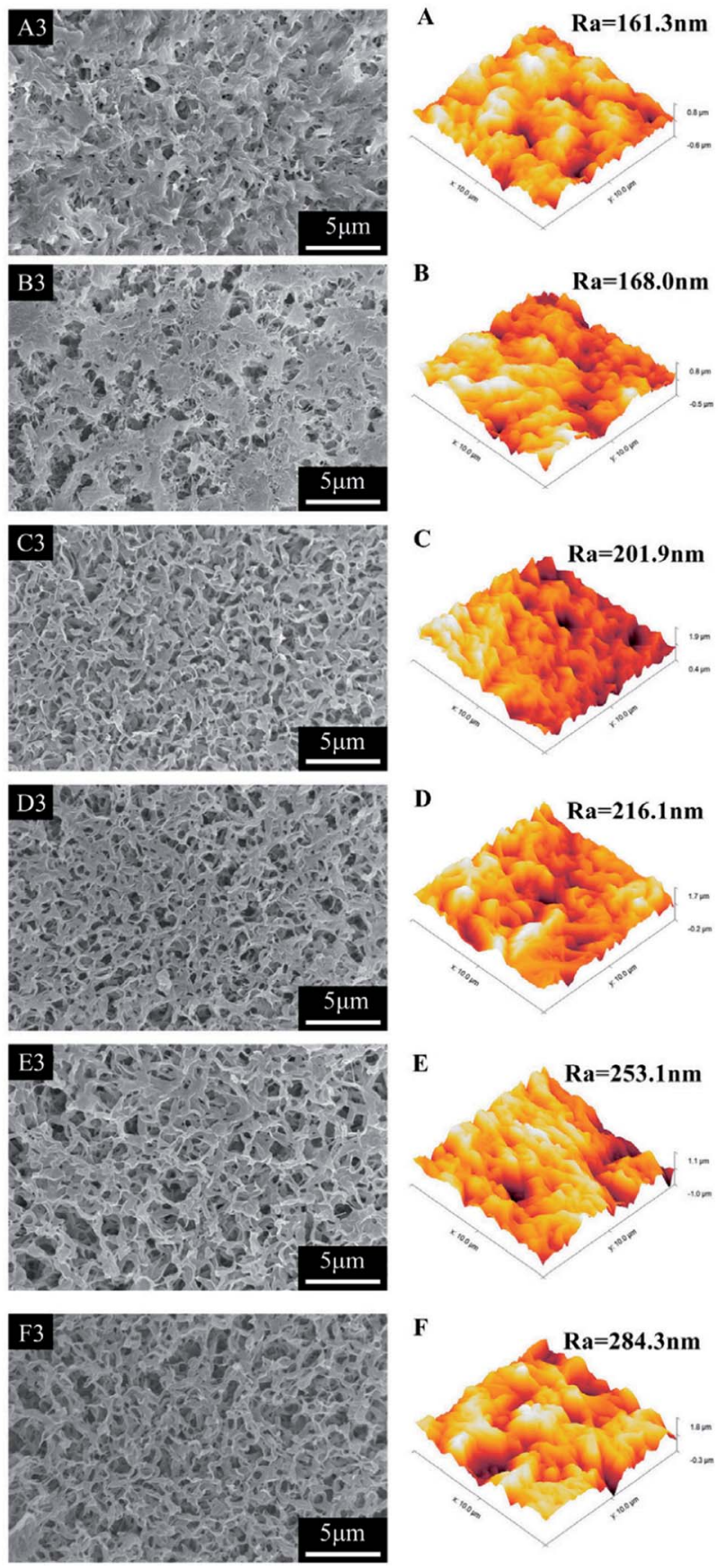

Fig. 2 The SEM and AFM images of PVDF-HFP/PTFE blend membranes (A-F): M-EO M-E5; 1: whole cross section, 2: enlarged cross section; 3: upper surface.

surface with low porosity and small pores. With the increase of PTFE content, the surface pore size got larger and surface porosity increased. The interaction between PVDF-HFP and mixed diluent was strong and PVDF-HFP was melted and dispersed into the mixed diluent. During cooling process, PVDF-HFP as film-forming polymer formed microporous membrane matrix. However, PTFE had high melting point and was dispersed into polymer solution as the form of particles. In case of constant overall polymer contents, the proportion of PTFE increased and the proportion of PVDF-HFP decreased relatively which resulted in the decrease of microporous membrane matrix, larger pores and looser structure. Furthermore, the viscosity of polymer solution also had an obvious effect on the membrane structure. According to the result of Fig. 1, the increase of PTFE content resulted in lower viscosity which accelerated the liquid-liquid phase separation and facilitated the formation of larger pores. ${ }^{31,32}$

The surface morphology, such as roughness, was an important factor for the change of contact angle. The AFM morphology and roughness parameters of obtained membranes 
Table 3 Porosity and mean pore size of PVDF-HFP/PTFE blend membranes

\begin{tabular}{lll}
\hline Membrane & Porosity $(\%)$ & Mean pore size $(\mathrm{nm})$ \\
\hline M-E0 & $45.9 \pm 3.7$ & $293.6 \pm 0.01$ \\
M-E1 & $54.5 \pm 2.1$ & $432.5 \pm 0.01$ \\
M-E2 & $61.5 \pm 1.7$ & $581.5 \pm 0.02$ \\
M-E3 & $68.4 \pm 2.5$ & $642.7 \pm 0.01$ \\
M-E4 & $73.0 \pm 0.8$ & $739.5 \pm 0.02$ \\
M-E5 & $75.9 \pm 0.7$ & $832.4 \pm 0.01$
\end{tabular}

were also shown in Fig. 2. It could be seen clearly that the surface roughness of obtained membranes increased with the increase of PTFE content. This was mainly due to the membrane structure changing looser and rougher with PTFE content increased.

In addition, mean pore size and porosity were also exhibited in Table 3. It could be seen that the mean pore size and porosity of PVDF-HFP/PTFE blend membranes obviously increased with introduction of PTFE particles. The decrease in the filmforming polymer (PVDF-HFP) content led to a loose microporous matrix membrane.

\subsection{Effects of PTFE content on selective wettability}

Lipophilic-hydrophobic or oleophobic-hydrophilic surface of membrane was a key factor for the oil/water separation efficiency. ${ }^{33}$ In order to investigate the selective wettability of the prepared membranes, a water or oil droplet was used to measure the water or oil contact angle. Fig. 3 showed static water contact angle of PVDF-HFP/PTFE blend membranes prepared with different PTFE contents. It can be seen clearly that the water contact angle of obtained membranes increased with addition of PTFE which had outstanding hydrophobicity. Without PTFE particles, the water contact angle of pure PVDFHFP membrane reached $113.2^{\circ}$ due to its own hydrophobicity. With addition of PTFE particles, the water contact angle of obtained membranes increased to $136.8^{\circ}$ which illustrated that the membranes had excellent hydrophobicity. The reason was

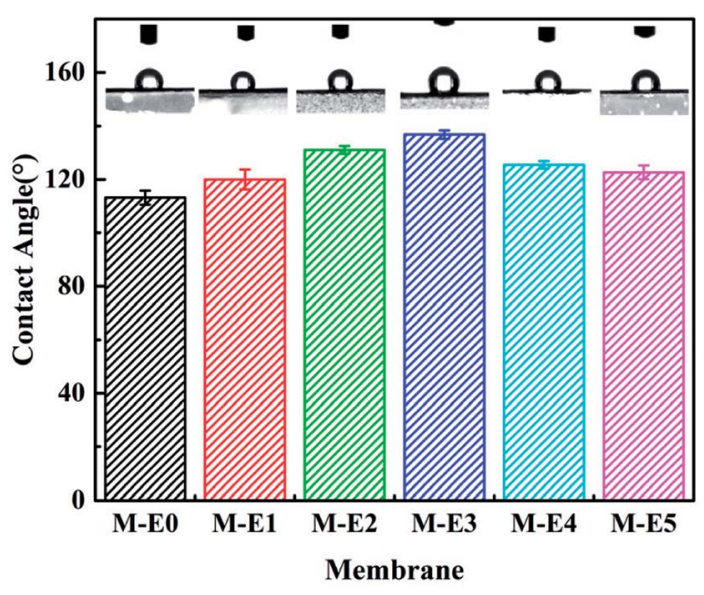

Fig. 3 Effect of PTFE content on the static water contact angle.

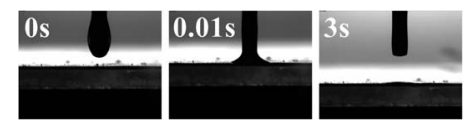

Fig. 4 Variation of oil (diesel) contact angle depended on time for upper surface of M-E3.

that the blending polymer PTFE possessed better hydrophobicity and weakened the surface free energy of obtained membranes. However, the water contact angle of obtained membrane decreased with further increase in PTFE content. It was because that the surface free energy of obtained membranes was close to that of PTFE particles with further increase of PTFE content. Additionally, the membrane pore size enlarged due to excess PTFE particles and water droplet was easily permeated into membrane through lager surface pores.

In this study, the lipophilicity of prepared membranes was determined by oil contact angle measurement. What an example to M-E3, as shown in Fig. 4, the oil droplet was dropped on membrane surface and spread out rapidly. At the same time, the oil droplet penetrated into membrane and oil contact angle decreased to almost $0^{\circ}$ within $3 \mathrm{~s}$ which illustrated an outstanding oil wettability of PVDF-HFP/PTFE blend membranes.

\subsection{Effects of PTFE content on permeability}

According to the hydrophobicity and lipophilicity of blend membranes, the oil (diesel) flux was determined to characterize the permeability which was mainly depended on the pore size and porosity. The membrane M-E0 without PTFE particles had a relatively low oil flux $\left(1386.5 \mathrm{~L} \mathrm{~m}^{-2} \mathrm{~h}^{-1}\right)$ owing to its dense surface structure with small pores and low porosity. Additionally, with increase of PTFE content, the mean pore size enlarged and porosity got higher which made the transmembrane pressure of oil through the membrane become smaller. When PTFE content was $15 \mathrm{wt} \%$, the oil flux was almost seven times greater than M-E0. The LEP increased with increase of PTFE content due to enhancement of hydrophobicity. However, when PTFE

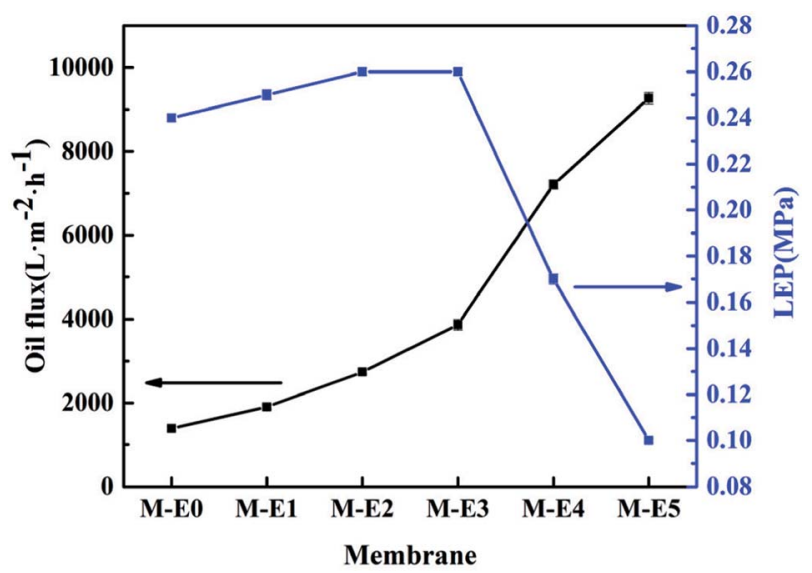

Fig. 5 Effect of the PTFE content on oil flux and LEP. 


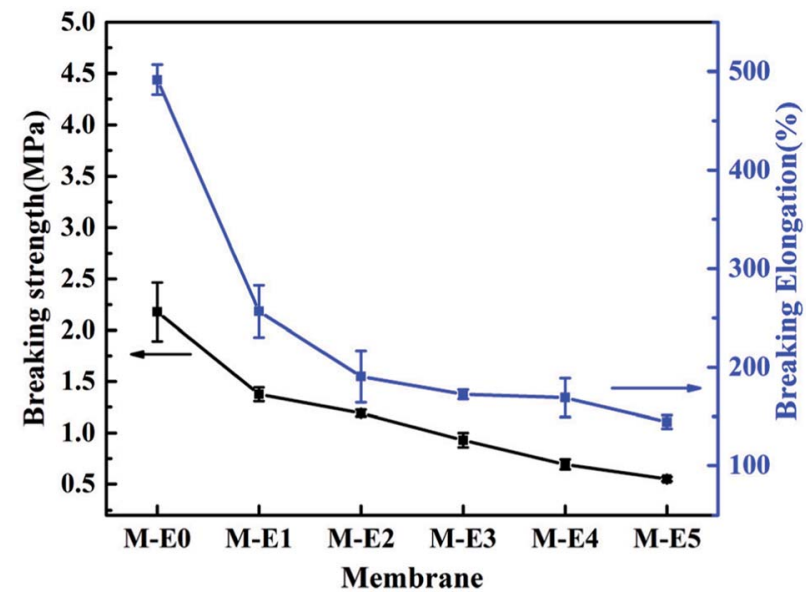

Fig. 6 Effect of the PTFE content on the mechanical properties.

content exceeded $12.5 \mathrm{wt} \%$, the LEP decreased dramatically owing to overlarge pores (Fig. 5).

\subsection{Effects of PTFE content on mechanical property}

The effect of PTFE content on the mechanical property was shown in Fig. 6. It was found that the breaking strength of M-E0 was much higher than other membranes. Furthermore, the breaking strength decreased with increase of PTFE content. During the cooling process, the molecular chain of film-forming polymer PVDF-HFP tangled and formed matrix membrane which constituted the skeleton of obtained membrane. When acted on a force, the breaking strength mainly depended on matrix membrane. Without addition of PTFE content, the viscosity of polymer solution was higher which resulted in more compact membrane skeleton and stronger chain entanglement. Hence, the breaking strength was larger. With increase of PTFE content, the film-forming polymer PVDF-HFP content decreased relatively and the viscosity of casting solution got smaller. During the cooling process, the growth resistance of poor phase was reduced and the rate of phase separation was high which resulted in looser membrane structure. Therefore, the breaking strength decreased with the increase of PTFE content.

In addition, the breaking elongation of blend membranes also exhibited a downward trend with the increase of PTFE content. On one hand, both PVDF-HFP and PTFE had lower surface energy which resulted in poor affinity between them. On the other hand, the chain entanglement got weaker and membrane structure became looser with increase of PTFE content.

\subsection{Separation performance for water-in-oil emulsions}

In order to investigate the oil/water separation performance of obtained PVDF-HFP/PTFE blend membranes, different emulsions, namely surfactant-free water-in-diesel emulsion (SFE-W/ D), surfactant-stabilized water-in-diesel emulsion (SSE-W/D), surfactant-free water-in-kerosene emulsion (SFE-W/K) and surfactant-stabilized water-in-kerosene emulsion (SSE-W/K), were prepared. In addition, the optical microscopy images
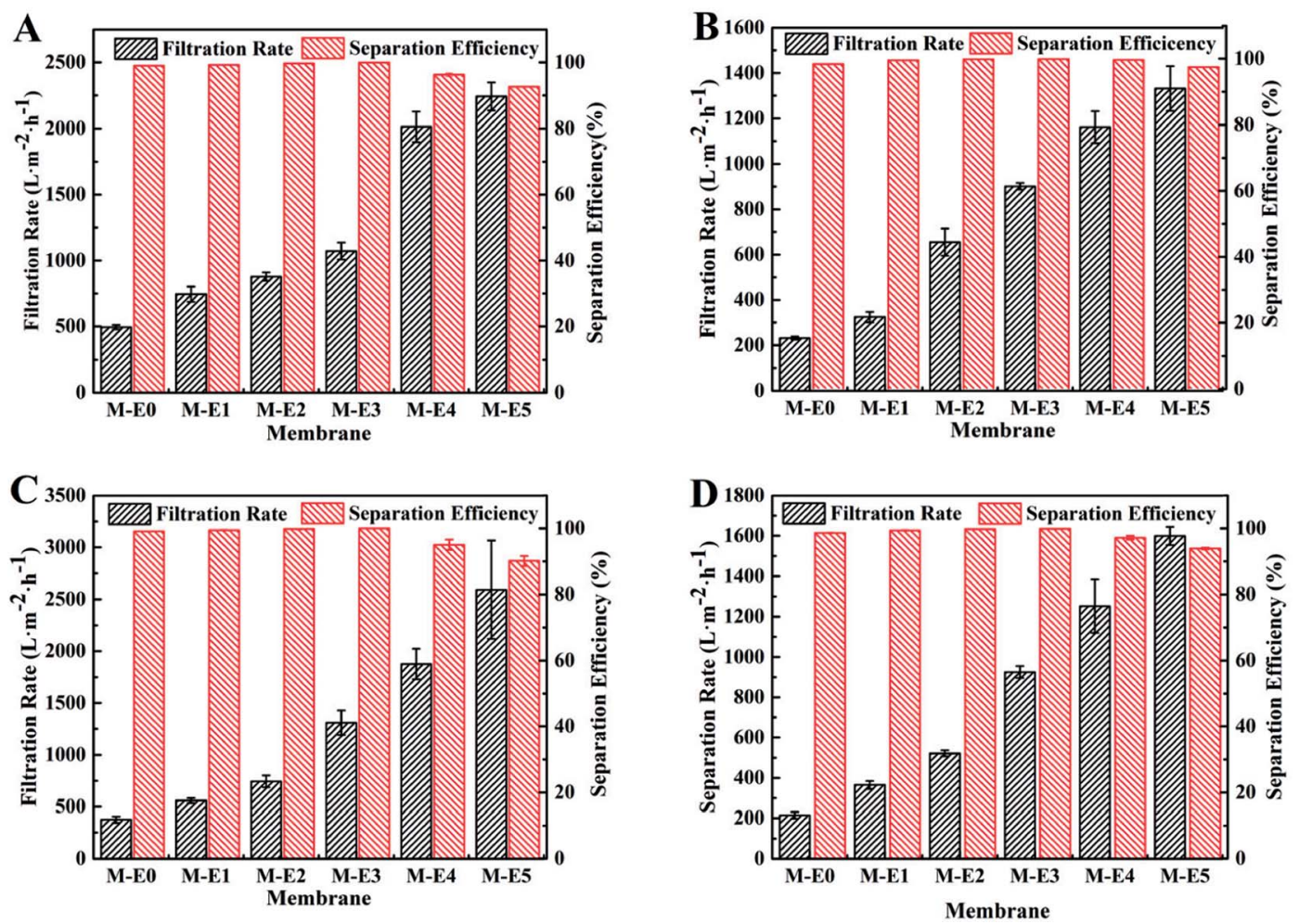

Fig. 7 Separation results for SFE-W/D (A), SSE-W/D (B), SFE-W/K (C) and SSE-W/K (D). 

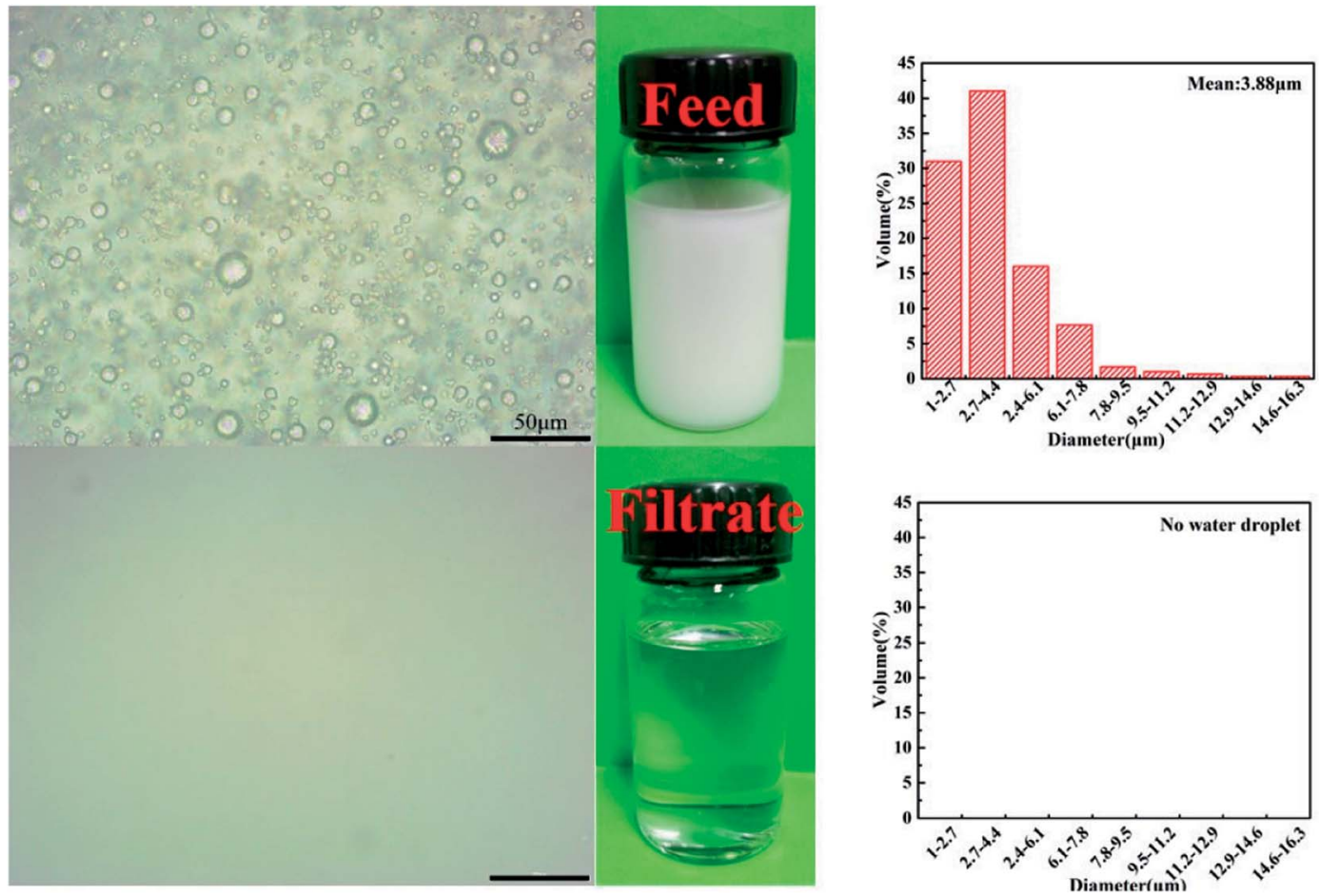

Fig. 8 Optical microscope images, photographs and size distribution of SSE-W/K.

and droplet distribution for separation results of SSE-W/K as an example for M-E3 were exhibited in Fig. 8.

From the results of Fig. 7, it was seen obviously that the filtration rate for different water-in-oil emulsions increased with increase of PTFE content. Furthermore, higher viscosity of diesel made the filtration rate of SFE-W/K was lower than that of SFE-W/D owing to higher trans-membrane resistance. This changing trend had a direct relation with the membrane structure what got looser with increase of PTFE content and enhanced the filtration rate of emulsions. Compare with the result of Fig. 3, it was found that the filtration rate for emulsions was much lower than the oil flux. Along with the continuous oil droplet permeated through the blend membrane into collection bottle, more and more water droplets were gathered in blend membrane surface and many surface pores were blocked which resulted in lower filtration rate for emulsions compared with pure oil flux. In addition, the demulsification process had an obvious effect on the filtration for surfactant-stabilized emulsions. Taking M-E3 as an example, the corresponding filtration rate for SFE-W/K and SSE-W/K was 1310 and $925 \mathrm{~L} \mathrm{~m}^{-2} \mathrm{~h}^{-1}$, respectively.

Although the filtration rate of pure PVDF-HFP membrane was low, the separation efficiency was up to $99 \%$ owing to its dense surface with small pores and its own hydrophobicity. With addition of PTFE particles, the surface became looser which resulted higher filtration rate. However, the separation efficiency was still higher than $99 \%$ owing to its better hydrophobicity. With further increase of PTFE content, the surface pore became too large which resulted in relatively low separation efficiency. The separation efficiency of SSE-W/K for M-E4, M-E5 was $97.2 \%$, 93.9\%, respectively. When high separation efficiency was maintained, the higher filtration rate, the more applicable for water-in-oil emulsions separation. According to above results, the membrane M-E3 was more applicable for water-in-oil emulsions separation.

During the long running time, unavoidable membrane fouling occurred, which led to lower filtration rate and separation efficiency. In this work, a repeating separation experiment was applied to evaluate the antifouling performance of the membrane M-E3. From Fig. 9, it could be seen that filtration rate had no obvious change with the increase of cycling times even up to 20 cycles. These results indicated an excellent antifouling property of the membrane M-E3. In addition,

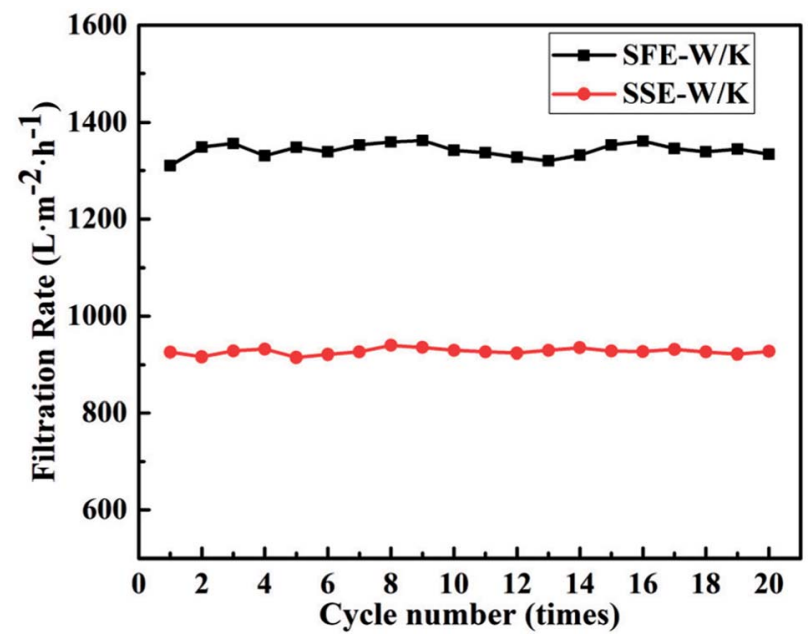

Fig. 9 Change of filtration rate with cycle times when separating SFE$\mathrm{W} / \mathrm{K}$ and SSE-W/K by M-E3. 
Table 4 The comparison of separation for surfactant-stabilized water-in-oil emulsion

\begin{tabular}{lllr}
\hline Separation efficiency $(\%)$ & Filtration rate $\left(\mathrm{L} \mathrm{m}^{-2} \mathrm{~h}^{-1}\right)$ & Membrane & Reference \\
\hline 99.6 & $300-400$ & ECTFE membranes & 11 \\
99.95 & $\approx 700$ & PVDF modified membranes & 34 \\
99.5 & $\approx 250$ & PVDF/PSMA composite membranes & 35 \\
$99.6-99.8$ & $100-30$ & PVDF membrane & 10 \\
$98-99.84$ & $250-450$ & PVDF-HFP membranes & 24 \\
$>99.85$ & $900-1000$ & PVDF-HFP/PTFE blend membrane (M-E3)
\end{tabular}

a comparison of separation performance for surfactantstabilized water-in-oil emulsions between the PVDF-HFP/PTFE blend membranes and other membranes reported in the literature has been made, as shown in Table 4. PVDF-HFP membrane possessed excellent hydrophobicity and desirable pore size which resulted in better separation performance for surfactant-stabilized water-in-oil emulsions. As shown in Table $\mathrm{S} 1$ in the ESI, $\dagger$ surface structure and properties of M-E3 showed no difference before and after immersion in $\mathrm{NaOH}$ solution which proved the possibility of the obtained membrane running in harsh environmental conditions for a long time.

\section{Conclusion}

PVDF-HFP/PTFE blend membranes were prepared for the first time via TIPS method with DBP and DOP as mixed diluent and the hydrophobic perfluoropolymer PTFE as the blending polymer. In addition, the structure and performance of obtained membranes was regulated by adjusting PTFE content in polymer. Without introduction of PTFE particles, the surface structure of obtained membrane was denser and the pore size was smaller. With the increase in PTFE content, the porosity, mean pore size and hydrophobicity increased obviously. Nevertheless, the breaking elongation and breaking strength decreased. The obtained PVDF-HFP/PTFE blend membranes exhibited outstanding hydrophobicity and lipophilicity because of low surface free energy. The obtained membrane could separate water-in-oil emulsions effectively. In consideration of filtration rate and separation efficiency, the membrane M-E3 was more applicable for water-in-oil emulsions separation.

\section{Conflicts of interest}

There are no conflicts to declare.

\section{Acknowledgements}

The National Natural Science Foundation of China (NFSC, 51673149), Industrial innovation project of THOA (BHSF201701 ) and the Science and Technology Plans of Tianjin (No. 15PTSYJC00240) supported this work. Thanks for the financial support.

\section{References}

1 C. H. Peterson, S. D. Rice, J. W. Short, D. Esler, J. L. Bodkin, B. E. Ballachey and D. B. Irons, Long-term ecosystem response to the Exxon Valdez oil spill, Science, 2003, 302, 2082-2086.

2 Y. Zhu, D. Wang, L. Jiang and J. Jin, Recent progress in developing advanced membranes for emulsified oil/water separation, NPG Asia Mater., 2014, 6, e101.

3 X. Zhu, A. Dudchenko, X. Gu and D. Jassby, Surfactantstabilized oil separation from water using ultrafiltration and nanofiltration, J. Membr. Sci., 2017, 529, 159-169.

4 W. Zhang, N. Liu, Y. Cao, Y. Chen, L. Xu, X. Lin and L. Feng, A Solvothermal Route Decorated on Different Substrates: Controllable Separation of an Oil/Water Mixture to a Stabilized Nanoscale Emulsion, Adv. Mater., 2015, 27, 7349-7355.

5 Y. Xiang, Y. Wang, H. Lin, Y. Wang, Z. Xiong and F. Liu, Efficient separation of $\mathrm{O} / \mathrm{W}$ and $\mathrm{W} / \mathrm{O}$ micro-emulsion by thermally responsive superantiwetting PVDF membrane, React. Funct. Polym., 2015, 97, 86-95.

$6 \mathrm{~T}$. Lim and X. Huang, In situ oil/water separation using hydrophobic-oleophilic fibrous wall: A lab-scale feasibility study for groundwater cleanup, J. Hazard. Mater., 2006, 137, 820-826.

7 Z. Xue, S. Wang, L. Lin, L. Chen, M. Liu, L. Feng and L. Jiang, A Novel Superhydrophilic and Underwater Superoleophobic Hydrogel-Coated Mesh for Oil/Water Separation, Adv. Mater., 2011, 23, 4270-4273.

8 J. Yong, Y. Fang, F. Chen, J. Huo, Q. Yang, H. Bian, G. Du and X. Hou, Femtosecond laser ablated durable superhydrophobic PTFE films with micro-through-holes for oil/water separation: Separating oil from water and corrosive solutions, Appl. Surf. Sci., 2016, 389, 1148-1155.

9 W. Zhang, Z. Shi, F. Zhang, X. Liu, J. Jin and L. Jiang, Superhydrophobic and superoleophilic PVDF membranes for effective separation of water-in-oil emulsions with high flux, Adv. Mater., 2013, 25, 2071-2076.

10 L. Chen, Y. Si, H. Zhu, T. Jiang and Z. Guo, A study on the fabrication of porous PVDF membranes by in situ elimination and their applications in separating oil/water mixtures and nano-emulsions, J. Membr. Sci., 2016, 520, 760-768.

11 J. Pan, C. Xiao, Q. Huang, H. Liu and T. Zhang, ECTFE hybrid porous membrane with hierarchical micro/nano-structural 
surface for efficient oil/water separation, J. Membr. Sci., 2017, 524, 623-630.

12 A. Venault, A. J. Jumao-as-Leyba, F.-C. Chou, D. Bouyer, I. J. Lin, T.-C. Wei and Y. Chang, Design of nearsuperhydrophobic/superoleophilic PVDF and PP membranes for the gravity-driven breaking of water-in-oil emulsions, J. Taiwan Inst. Chem. Eng., 2016, 65, 459-471.

13 M. C. Garcia-Payo, M. Essalhi and M. Khayet, Effects of PVDF-HFP concentration on membrane distillation performance and structural morphology of hollow fiber membranes, J. Membr. Sci., 2010, 347, 209-219.

14 A. M. Stephan, K. S. Nahm, M. A. Kulandainathan, G. Ravi and J. Wilson, Poly(vinylidene fluoridehexafluoropropylene) (PVdF-HFP) based composite electrolytes for lithium batteries, Eur. Polym. J., 2006, 42, 1728-1734.

$15 \mathrm{X}$. Tian and X. Jiang, Poly(vinylidene fluoride-cohexafluoropropene) (PVDF-HFP) membranes for ethyl acetate removal from water, J. Hazard. Mater., 2008, 153, 128-135.

16 B. S. Lalia, E. Guillen-Burrieza, H. A. Arafat and R. Hashaikeh, Fabrication and characterization of polyvinylidenefluoride-co-hexafluoropropylene (PVDF-HFP) electrospun membranes for direct contact membrane distillation, J. Membr. Sci., 2013, 428, 104-115.

17 S. Wongchitphimon, R. Wang and R. Jiraratananon, Surface modification of polyvinylidene fluoride- $\mathrm{Co}$ hexafluoropropylene (PVDF-HFP) hollow fiber membrane for membrane gas absorption, J. Membr. Sci., 2011, 381, 183-191.

18 B. S. Lalia, Y. A. Samad and R. Hashaikeh, Nanocrystallinecellulose-reinforced poly(vinylidenefluoride-cohexafluoropropylene) nanocomposite films as a separator for lithium ion batteries, J. Appl. Polym. Sci., 2012, 126, e441-e447.

19 G. Ji, Y. Xu, B. Zhu and L. Zhu, PVDF-HFP Membrane Prepared via TIPS Process as the Matrix of Gel Electrolyte for Lithium Ion Battery, J. Macromol. Sci., Part B: Phys., 2011, 50, 275-290.

20 Z. Cui, Y. Xu, L. Zhu, H. Deng, J. Wang and B. Zhu, Preparation of PVDF-HFP Microporous Membranes via the Thermally Induced Phase Separation Process, J. Macromol. Sci., Part B: Phys., 2009, 48, 41-54.

21 Z. Cui, Y. Xu, L. Zhu, J. Wang and B. Zhu, Investigation on PVDF-HFP microporous membranes prepared by TIPS process and their application as polymer electrolytes for lithium ion batteries, Ionics, 2009, 15, 469-476.

22 J. Cao, B. Zhu, Y. Xu, J. Li and C. Chen, Preparation and characterization of PVDF-HFP membrane, J. Macromol. Sci., Part A: Pure Appl.Chem., 2008, 45, 449-455.
23 H. Cao, W. Gu, J. Fu, Y. Liu and S. Chen, Preparation of superhydrophobic/oleophilic copper mesh for oil-water separation, Appl. Surf. Sci., 2017, 412, 599-605.

24 X. Wang, C. Xiao, H. Liu, Q. Huang, J. Hao and H. Fu, Poly(vinylidene Fluoride-Hexafluoropropylene) Porous Membrane with Controllable Structure and Applications in Efficient Oil/Water Separation, Materials, 2018, 11, 443-454.

25 J. Zhang, Q. Xue, X. Pan, Y. Jin, W. Lu, D. Ding and Q. Guo, Graphene oxide/polyacrylonitrile fiber hierarchicalstructured membrane for ultra-fast microfiltration of oilwater emulsion, Chem. Eng. J., 2017, 307, 643-649.

26 J. Zhang, X. Pan, Q. Xue, D. He, L. Zhu and Q. Guo, Antifouling hydrolyzed polyacrylonitrile/graphene oxide membrane with spindle-knotted structure for highly effective separation of oil-water emulsion, J. Membr. Sci., 2017, 532, 38-46.

27 G. Kang and Y. Cao, Application and modification of poly(vinylidene fluoride) (PVDF) membranes-A review, $J$. Membr. Sci., 2014, 463, 145-165.

28 M. M. Teoh, T. S. Chung and Y. S. Yeo, Dual-layer PVDF/PTFE composite hollow fibers with a thin macrovoid-free selective layer for water production via membrane distillation, Chem. Eng. J., 2011, 171, 684-691.

29 L. Zheng, J. Wang, J. Li, Y. Zhang, K. Li and Y. Wei, Preparation, evaluation and modification of PVDF-CTFE hydrophobic membrane for MD desalination application, Desalination, 2017, 402, 162-172.

30 H. J. Kim and I. C. Um, Relationship between rheology and electro-spinning performance of regenerated silk fibroin prepared using different degumming methods, J. Rheol., 2014, 26, 119-125.

31 G. Ji, L. Zhu, B. Zhu, C. Zhang and Y. Xu, Structure formation and characterization of PVDF hollow fiber membrane prepared via TIPS with diluent mixture, J. Membr. Sci., 2008, 319, 264-270.

32 B. Li, L. Wu, L. Li, S. Seeger, J. Zhang and A. Wang, Superwetting double-layer polyester materials for effective removal of both insoluble oils and soluble dyes in water, ACS Appl. Mater. Interfaces, 2014, 6, 11581-11588.

33 C. H. Lee, N. Johnson, J. Drelich and Y. K. Yap, The performance of superhydrophobic and superoleophilic carbon nanotube meshes in water-oil filtration, Carbon, 2011, 49, 669-676.

34 W. Zhang, Z. Shi, F. Zhang, X. Liu, J. Jin and L. Jiang, Superhydrophobic and Superoleophilic PVDF Membranes for Effective Separation of Water-in-Oil Emulsions with High Flux, Adv. Mater., 2013, 25, 2071-2076.

35 X. Yuan, W. Li, Z. Zhu, N. Han and X. Zhang, Thermoresponsive PVDF/PSMA composite membranes with micro/ nanoscale hierarchical structures for oil/water emulsion separation, Colloids Surf., A, 2017, 516, 305-316. 